\title{
Partial characterization and anticoagulant activity of a heterofucan from the brown seaweed Padina gymnospora
}

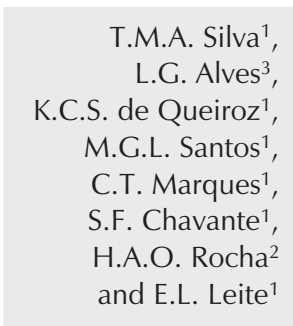

\author{
Laboratórios de ${ }^{1}$ Glicobiologia and ${ }^{2} B$ iotecnologia de Polímeros Naturais, \\ Departamento de Bioquímica, Universidade Federal do Rio Grande do Norte, \\ Natal, RN, Brasil \\ ${ }^{3}$ Departamento de Bioquímica, Escola Paulista de Medicina, \\ Universidade Federal de São Paulo, São Paulo, SP, Brasil
}

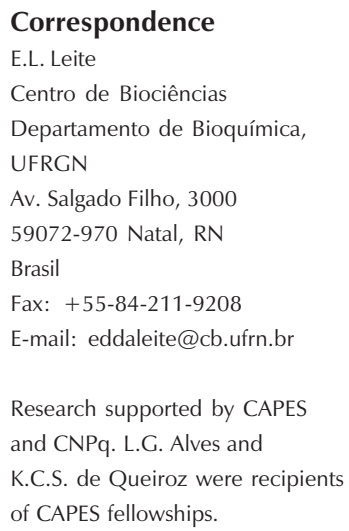

Received November 18, 2003 Accepted October 29, 2004

\begin{abstract}
The brown algae Padina gymnospora contain different fucans. Powdered algae were submitted to proteolysis with the proteolytic enzyme maxataze. The first extract of the algae was constituted of polysaccharides contaminated with lipids, phenols, etc. Fractionation of the fucans with increasing concentrations of acetone produced fractions with different proportions of fucose, xylose, uronic acid, galactose, and sulfate. One of the fractions, precipitated with $50 \%$ acetone $(\mathrm{v} / \mathrm{v})$, contained an 18-kDa heterofucan (PF1), which was further purified by gel-permeation chromatography on Sephadex G-75 using $0.2 \mathrm{M}$ acetic acid as eluent and characterized by agarose gel electrophoresis in 0.05 M 1,3 diaminopropane/acetate buffer at $\mathrm{pH} 9.0$, methylation and nuclear magnetic resonance spectroscopy. Structural analysis indicates that this fucan has a central core consisting mainly of 3-B-Dglucuronic acid $1 \rightarrow$ or $4-\beta$-D-glucuronic acid $1 \rightarrow$, substituted at C-2 with $\alpha$-L-fucose or $\beta$-D-xylose. Sulfate groups were only detected at C-3 of 4- $\alpha$-L-fucose $1 \rightarrow$ units. The anticoagulant activity of the PF1 (only 2.5-fold lesser than low molecular weight heparin) estimated by activated partial thromboplastin time was completely abolished upon desulfation by solvolysis in dimethyl sulfoxide, indicating that 3-Osulfation at C-3 of $4-\alpha$-L-fucose $1 \rightarrow$ units is responsible for the anticoagulant activity of the polymer.
\end{abstract}

Key words

- Fucan

- Anticoagulant activity

- Sulfated polysaccharides

- Brown algae

- Padina gymnospora

\section{Introduction}

Brown algae contain a wide variety of acid polysaccharides such as the alginic acids, consisting exclusively of uronic acid, the homo fucans, consisting of sulfated fucan, and the heterofucans, that contain portions of other neutral sugars and uronic acids in addition to sulfated fucose $(1,2)$. In these cases, branches, a complex distribution of sulfate and occasionally acetyl groups may be observed $(3,4)$.

All algal fucans have complex structures but recent studies have revealed ordered repeated units in homofucans from several species. These studies clearly show that several homofucans have large proportions of both $\alpha-(1 \rightarrow 3)$ and $\alpha-(1 \rightarrow 4)$ glycosidic link- 
ages with sulfate groups at C-2, without excluding the presence of other sulfates, acetyl groups or branches at positions 2, 3 or $4(5,6)$. Furthermore, little is known about the structural features of the heterofucans. Most of the difficulties of structural studies arise from the fact that these compounds are very heterogeneous, yielding complex nuclear magnetic resonance (NMR) spectra with broad signals and thereby interfering with resolution. In fact, for these algal polysaccharides even high-field NMR provides data of limited value, and complete descriptions of their structures are not available (7).

Since the first description of fucans from algae, these polysaccharides have been tested for biological activities in different mammalian systems. Algal fucans have anticoagulant/antithrombotic $(5,8,9)$, anticomplement (10), antiproliferative (11), antiviral (12), and antiadhesive activities (13). However, the relationship between structure and biological activity of fucans has not been fully elucidated.

Several homofucans with demonstrated anticoagulant activity have been extracted from different brown seaweeds $(5,14)$. However, there are only few reports of their mechanism of action. In general, the proposed mechanism is predominantly mediated by antithrombin and/or heparin co-factor II.

The composition of algal fucans varies according to species (15), extraction procedure (8), season of harvest, and local climatic conditions (2). Thus, each newly described fucan is a unique compound with unique structural features, consequently having the potential of being used as a novel drug.

On the basis of these considerations, the purpose of the present study was to obtain heterofucans from the seaweed Padina gymnospora, to compare their anticoagulant activity with heparin and low molecular weight heparin and to determine the structural requirement for anticoagulant activity.

\section{Material and Methods}

\section{Material}

Chemicals of analytical grade were purchased from Quimis (São Paulo, SP, Brazil), Vetec (São Paulo, SP, Brazil) and Merck (São Paulo, SP, Brazil). Chondroitin 4-sulfate was purchased from Miles Laboratories (Elkhart, IN, USA). Propylenediamine (1,3diaminopropane) was purchased from Aldrich (Milwaukee, WI, USA). Heparan sulfate, dermatan sulfate, glucose, glucuronic acid, xylose, fucose, galactose, and mannose were purchased from Sigma (St. Louis, MO, USA). Standard Low-mr agarose was purchased from BioRad (Richmond, CA, USA). Heparin from bovine lung (175 IU) was a gift from Dr. Carl Peter von Dietrich, Department of Biochemistry, UNIFESP.

\section{Extraction and purification}

The marine alga Padina gymnospora was collected along the southern coast of Natal, $\mathrm{RN}$, Brazil. Immediately after collection, the algae were identified by Dr. Heliane Marinho from Centro de Biociências/UFRN, Natal, $\mathrm{RN}$, Brazil. The algae were stored in our laboratories and dried at $50^{\circ} \mathrm{C}$ under ventilation in an oven, ground in a blender and incubated with acetone to eliminate lipids and pigments. About $50 \mathrm{~g}$ of powdered algae was suspended with 5 volumes of $0.25 \mathrm{M}$ $\mathrm{NaCl}$ and the $\mathrm{pH}$ was adjusted to 8.0 with $\mathrm{NaOH}$. Ten milligrams maxataze, an alkaline protease from Esporobacillus (BioBrás, Montes Claros, MG, Brazil), was then added to the mixture for proteolytic digestion. After incubation for $24 \mathrm{~h}$ at $60^{\circ} \mathrm{C}$ under shaking and periodical adjustments of $\mathrm{pH}$, the mixture was filtered through cheesecloth and precipitated with 0.3 volumes of ice-cold acetone under gentle shaking at $4^{\circ} \mathrm{C}$. The solution was left to stand at the same temperature for an additional $24 \mathrm{~h}$. The precipitate formed was collected by centrifugation at 
$10,000 \mathrm{~g}$ for $20 \mathrm{~min}$, dried under vacuum, resuspended in distilled water, and analyzed. Acetone at $0.5,0.8,1.0$ and 1.5 volumes, calculated from the initial solution, was added to the supernatant and precipitated as described above. Five fractions were obtained and were named according to the volumes of acetone used. The fraction precipitated with 1.0 volume of acetone was subjected to gelpermeation chromatography on Sephadex G-75 (120 x $1.8 \mathrm{~cm})$, using $0.2 \mathrm{M}$ acetic acid as eluent. The elution was monitored for uronic acid (16) and total sugar (17). The polysaccharides eluted were dialyzed against water, freeze-dried and used in the anticoagulant assays.

\section{Chemical methods and composition}

The content of uronic acid (16), fucose (18) and total sugars (17) was estimated by colorimetric methods. After acid hydrolysis of the polysaccharides $\left(6 \mathrm{~N} \mathrm{HCl}, 100^{\circ} \mathrm{C}, 6 \mathrm{~h}\right)$ sulfate content was measured by a turbidimetric method, as described previously (19). The sugar composition of the polymers was determined by paper chromatography in isobutyric acid: $1 \mathrm{M} \mathrm{NH}_{4} \mathrm{OH}, 5: 3(\mathrm{v} / \mathrm{v})$, or nbutanol:pyridine: water, $3: 1: 1$ by volume, for $24 \mathrm{~h}$ and by gas-liquid chromatography of derived alditol acetates (20). The type of uronic acid was determined by electrophoresis on Whatman No. $3 \mathrm{MM}$ paper in $0.25 \mathrm{M}$ ammonium formate buffer, $\mathrm{pH} 2.7$, at $300 \mathrm{~V}$ (21). Protein content was measured by the method of Lowry et al. (22).

\section{Agarose gel electrophoresis}

Agarose gel electrophoresis of the acid polysaccharides was performed on $0.6 \%$ agarose gels $(7.5 \times 10 \mathrm{~cm}, 0.2 \mathrm{~cm}$ thick) prepared in four different buffers: $0.05 \mathrm{M} 1,3-$ diaminopropane/acetate buffer, $\mathrm{pH} 9.0$; discontinuous buffer containing $0.04 \mathrm{M}$ barium acetate, $\mathrm{pH} 4.0 / 0.05 \mathrm{M}$ diaminopropane acetate, $\mathrm{pH} 9.0$, and $0.05 \mathrm{M}$ phosphate buffer,
pH 8.0, as described by Dietrich et al. (23). Aliquots of the fractions (about $50 \mu \mathrm{g}$ ) were applied to the gel and run for $1 \mathrm{~h}$ at $100 \mathrm{~V}$. The compounds in the gel were fixed with $0.1 \%$ $\mathrm{N}$-cetyl-N,N,N-trimethylammonium bromide for $4 \mathrm{~h}$. The gel was dried and stained for 15 min with $0.1 \%$ Toluidine blue in acetic acid:ethanol:water (0.1:5:4.9, v/v) and destained with the same solution without Toluidine blue. For visualization of the polyuronides, the gel was restained with Toluidine blue and destained with $0.1 \mathrm{M}$ sodium acetate buffer, $\mathrm{pH} 4.2$ (24).

\section{Desulfation of PF1}

About $20 \mathrm{mg}$ of the polysaccharide was dissolved in $5 \mathrm{ml}$ of distilled water and mixed with $1 \mathrm{~g}$ (dry weight) of Dowex 50-W $\left(\mathrm{H}^{+}\right.$, 200-400 mesh). After neutralization with pyridine, solutions were lyophilized. The resulting pyridinium salt was dissolved in $2.5 \mathrm{ml}$ dimethyl sulfoxide:methanol (9:1, v/v) (25). The mixture was heated at $80^{\circ} \mathrm{C}$ for $4 \mathrm{~h}$, and the desulfated products were exhaustively dialyzed against distilled water and lyophilized. The extent of desulfation was estimated by the molar ratio of sulfate/total sugar $(17,19)$.

\section{Carboxyreduction and methylation}

Native and desulfated fucans were reduced using $\mathrm{NaBD}_{4}$ and 1-cyclohexyl-3-(2morpholinoethyl) carbodiimide metho-p-toluene sulfonate as described previously (20). Polysaccharides $(10 \mathrm{mg}$ ) were subjected to three rounds of methylation as described $(26,27)$. Methylated polymers were hydrolyzed in $6 \mathrm{M}$ trifluoroacetic acid for $5 \mathrm{~h}$ at $100^{\circ} \mathrm{C}$ and reduced with $\mathrm{NaBD}_{4}$ and the alditols were acetylated with acetic anhydride:pyridine $(1: 1, \mathrm{v} / \mathrm{v})(28)$. The alditol acetates of methylated sugars were dissolved in chloroform and analyzed with a gas chromatograph/mass spectrometer model 5890; Hewlett Packard. 


\section{Fourier transform-infrared spectroscopy}

The Fourier transform-infrared spectrum (FT-IR) was recorded with an IR spectrophotometer (model 8300; Shimadzu, Tokyo, Japan) between 400 and $4000 \mathrm{~cm}^{-1}$. The samples $(10 \mathrm{mg})$ were analyzed as a $\mathrm{KBr}$ pellet.

\section{${ }^{13}$ C-NMR}

Fifty milligrams of the sample was dissolved in $\mathrm{D}_{2} \mathrm{O}$ and the ${ }^{13} \mathrm{C}-\mathrm{NMR}$ spectrum obtained using a Bruker (DRX 600; Bremen, Germany) spectrometer at $60^{\circ} \mathrm{C}$.

\section{Anticoagulant activity}

The activated partial thromboplastin time (aPTT) was determined using citrated normal human plasma according to the manufacturer specifications (Labtest, São Paulo, SP, Brazil). For the prothrombin time (PT) assay, $90 \mu$ l of citrated normal human plasma was mixed with $10 \mu \mathrm{l}$ of a purified fucan F1 (PF1) solution at different concentrations and incubated for $1 \mathrm{~min}$ at $37^{\circ} \mathrm{C}$. The PT assay reagent $(200 \mu \mathrm{l})$, preincubated for 10 min at $37^{\circ} \mathrm{C}$, was then added and the clotting time recorded with a Quick Times coagulometer (Drake Ltda., São Paulo, SP, Brazil).

\section{Results}

Fractionation and sugar composition of the polysaccharides from the different acetone fractions

The compositions of the polysaccharides obtained from different acetone fractions are shown in Table 1. With the exception of fraction 0.3 , all fractions contained uronic acid, xylose, galactose, fucose, sulfate, and a small amount of protein (0.6-5.8\%). However, differences in the relative proportions of the sugars were observed when the fractions obtained with different volumes of acetone were compared. Thus, uronic acid was the main sugar present in the polymers precipitated with $0.3,0.5$ and 0.8 volumes of acetone. The higher content of uronic acid in these fractions may be explained by the presence of alginic acid. Furthermore, neutral sugars were found in larger amounts in fractions 1.0 and 1.5. Since glucose was not detected, it is unlikely that these fractions were contaminated with laminarans, a group of $\beta$-D-glucans found in brown algae.

\section{Agarose gel electrophoresis analysis of the polysaccharides from the different acetone fractions}

The polysaccharides from the different acetone fractions were subjected to agarose gel electrophoresis in diaminopropaneacetate buffer (Figure 1A). Electrophoresis revealed the presence of two or three bands in several fractions while the fractions obtained with 1.0 and 1.5 volumes of acetone showed a single band each. Figure 1B shows the same agarose gel restained and destained with sodium acetate buffer. This procedure revealed the presence of a fourth compound (alginic acid) in the fractions obtained with 0.3 and 0.8 volumes of acetone.

Fractions 1.0 and 1.5 were found to be more homogeneous than the other fractions, but, due to the small amount of fraction 1.5 (Table 1), we chose fraction 1.0 for further study. This fucan showed a single component by agarose gel electrophoresis and high anticoagulant activity compared to the other polysaccharides.

\section{Purification and chemical characterization of fraction $\mathbf{1 . 0}$}

Fraction 1.0 was applied to a Sephadex G-75 column (Figure 2) and eluted with 0.2 $\mathrm{M}$ acetic acid. Fractions of approximately 
Table 1. Partial chemical composition of acidic polysaccharides obtained from Padina gymnospora by acetone precipitation.

\begin{tabular}{|c|c|c|c|c|c|c|c|c|}
\hline \multirow{2}{*}{$\begin{array}{l}\text { Fraction } \\
\text { (acetone } \\
\text { volume) }\end{array}$} & \multirow{2}{*}{$\begin{array}{l}\text { Total } \\
\text { sugar } \\
(\%)^{*}\end{array}$} & \multirow{2}{*}{$\begin{array}{c}\text { Protein } \\
(\%)^{*}\end{array}$} & \multicolumn{6}{|c|}{ Molar ratio } \\
\hline & & & Fucose & Xylose & Uronic acid & Galactose & Mannose & Sulfate \\
\hline 0.3 & 38.7 & 5.8 & 1 & 0.1 & 2.6 & - & 0.1 & 1.2 \\
\hline 0.5 & 16.0 & 4.6 & 1 & 0.5 & 3.1 & 0.6 & - & 2.5 \\
\hline 0.8 & 26.0 & 3.2 & 1 & 0.6 & 2.7 & 0.4 & - & 0.6 \\
\hline 1.0 & 16.0 & 1.6 & 1 & 0.4 & 1.5 & 0.3 & $<0.001$ & 1.5 \\
\hline 1.5 & 3.2 & 0.6 & 1 & 0.3 & 1.0 & 0.2 & - & 1.3 \\
\hline
\end{tabular}

${ }^{*}$ Calculated in relation to total weight. Acetone volume is volume of acetone added to 1.0 volume of extract.
A

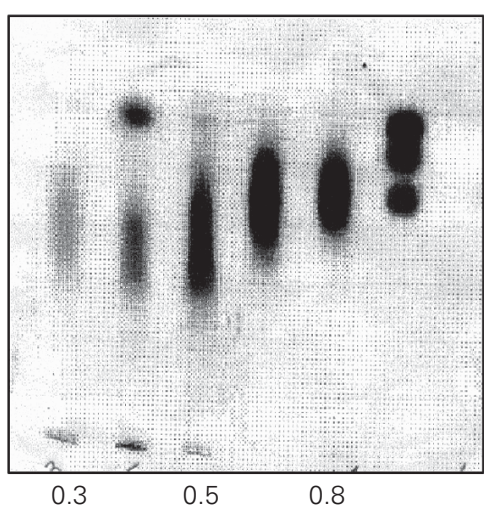

B

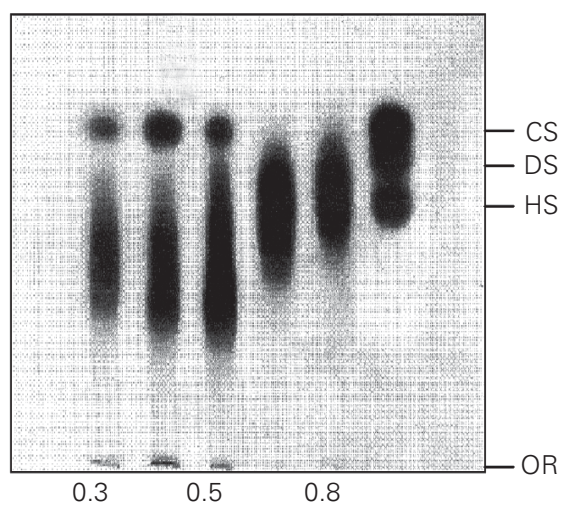

Figure 1. Agarose gel electrophoresis of sulfated fucans extracted from Padina gymnospora. Sulfated fucans were extracted after maxataze digestion and partially purified by acetone precipitation. The sulfated fucans $(50 \mu \mathrm{g})$ were applied to $0.5 \%$ agarose, and electrophoresis was carried out for $1 \mathrm{~h}$ at $110 \mathrm{~V}$ in 0.05 M 1,3-diaminopropane/acetate, pH 9.0. Gels were then maintained in $0.1 \% \mathrm{~N}$-cetyl-N,N,N-trimethylammonium bromide solution for $4 \mathrm{~h}$ and dried. The polysaccharides in the gel were stained with $0.1 \%$ Toluidine blue in acetic acid/ethanol/water $(0.1: 1: 5, \mathrm{v} / \mathrm{v})$ for $15 \mathrm{~min}$ and destained with acetic acid/ethanol/water $(0.1: 1: 5, \mathrm{v} / \mathrm{v})(\mathrm{A})$ or with $0.1 \mathrm{M}$ sodium acetate, $\mathrm{pH}$ 4.0, in water for $5 \mathrm{~min}$ (B). Standard of glycosaminoglycans: chondroitin sulfate (CS), dermatan sulfate (DS) and heparan sulfate (HS), $5 \mu \mathrm{g}$ each. $\mathrm{OR}=$ origin. The definition of acetone fractions is given in the legend to Table 1.)

Figure 2. Gel filtration of fraction 1.0. The fraction precipitated with 1.0 volume of acetone was applied to a Sephadex G-75 column $(1.8 \times 120 \mathrm{~cm})$. The column was eluted with $0.2 \mathrm{M}$ acetic acid, 1-ml fractions were collected and the effluent was analyzed for the presence of sugars by the phenol- $\mathrm{H}_{2} \mathrm{SO}_{4}$ method (20). The arrows indicate the void volume $\left(V_{0}\right)$ and the total volume $\left(V_{t}\right)$. 
$1 \mathrm{ml}$ were collected. Two peaks were obtained and denoted PF1 (fraction numbers 34-54), with 18,000 kDa, and PF2 (fraction numbers 56-82). The chemical composition of PF1 and PF2 is shown in Table 2. PF1 is a heterofucan with a high content of uronic acid and low contamination with protein. Electrophoresis in formate buffer showed that glucuronic acid is the single uronic acid present in PF1. PF2 showed a higher level of contamination with proteins and was discarded. PF1 was subjected to agarose gel electrophoresis using three different buffer systems (Figure 3). In all of them PF1 migrated as a single component, showing

Table 2. Partial chemical composition of the polysaccharide fractions obtained from the Sephadex G-75 column.

\begin{tabular}{lcc}
\hline Fraction & PF1 & PF2 \\
\hline Polysaccharides $(\%)^{*}$ & 78 & 32 \\
Protein $(\%)^{* *}$ & 0.6 & 50 \\
Molar ratios & & \\
$\quad$ Fucose & 1 & 1 \\
Xylose & 0.3 & 0.2 \\
Uronic acid & 1.3 & 1.2 \\
Galactose & 0.2 & 0.15 \\
Mannose & Trace & - \\
Sulfate & 0.4 & 0.3 \\
\end{tabular}

${ }^{*}$ Determined by the phenol- $\mathrm{H}_{2} \mathrm{SO}_{4}$ reaction (17). ${ }^{*}$ Calculated in relation to total weight.
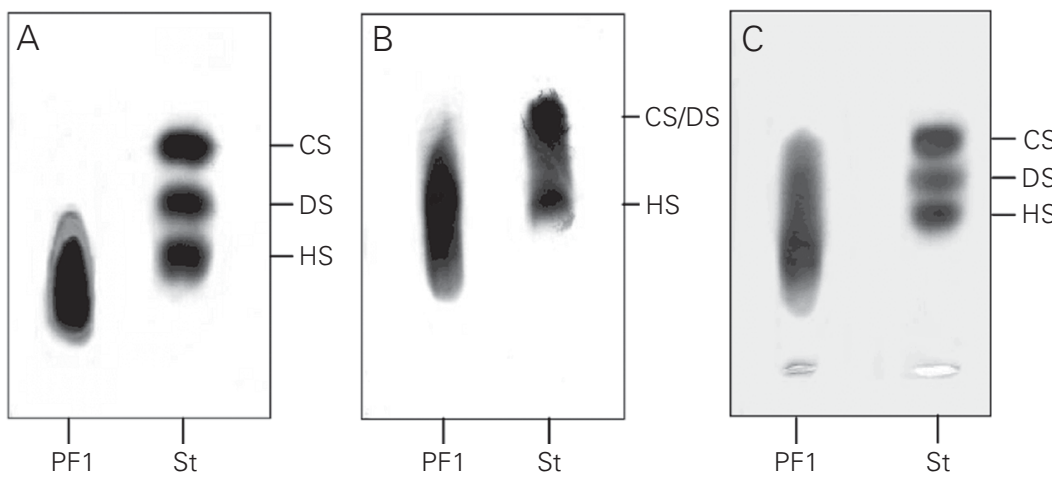

Figure 3. Agarose gel electrophoresis of fraction PF1. Fraction PF1 $(50 \mu \mathrm{g})$ obtained from the Sephadex G-75 column was subjected to electrophoresis in $40 \mathrm{mM}$ barium acetate buffer, $\mathrm{pH} 4.0$ (A); $50 \mathrm{mM}$ sodium phosphate buffer, $\mathrm{pH} 8.0$ (B); $50 \mathrm{mM}$ diaminopropane/ acetate buffer, $\mathrm{pH} 9.0$ (C) as described in Material and Methods. St = standard of glycosaminoglycans: chondroitin sulfate (CS), dermatan sulfate (DS) and heparan sulfate (HS), $5 \mu \mathrm{g}$ each. once again that the compound was essentially homogeneous and free of other acidic polysaccharide fractions.

\section{Fourier transform-infrared spectra of PF1}

The FT-IR spectra of PF1 showed an intense absorption band at $1264 \mathrm{~cm}^{-1}(\mathrm{~S}=\mathrm{O})$ common to all sulfate esters (Figure 4). An additional sulfate absorption band at 822 $\mathrm{cm}^{-1}$ (C-O-S, equatorial sulfate) indicated that most sulfate groups are located at positions 2 and/or 3. Absorption bands at 3330 $\mathrm{cm}^{-1}$ and $1648 \mathrm{~cm}^{-1}$ correspond to hydroxyl and carboxyl groups, respectively. In addition, we did not find absorption bands around $1720 \mathrm{~cm}^{-1}$, which would have indicated the presence of O-acetyl groups.

\section{${ }^{13}$ C-NMR spectroscopy of PF1}

The ${ }^{13} \mathrm{C}-\mathrm{NMR}$ spectrum of PF1 (Figure 5) showed peaks at 101-101.5 ppm corresponding to $\mathrm{C}-1$ of $4-\alpha-\mathrm{L}-$ fucose and 3 $\left(\mathrm{OSO}_{3}\right)-1$ and $\mathrm{C}-1$ of $3-\alpha-\mathrm{L}-$ fucose- 1 , respectively. The signals at $77.5 \mathrm{ppm}(\mathrm{C}-3)$, 80.5 ppm (C-4) and 18 ppm (C-6) confirmed the presence of sulfated fucose. The same spectrum also showed peaks at 105.0-106.2 ppm corresponding to $B$-D-glucuronic acid and 103.2 corresponding to $4-\beta-D-x y l o s e-1$, in agreement with the methylation analysis. Absorption at $99.0 \mathrm{ppm}$ may correspond to 3,6-di-substituted B-D-galactose. Minor signals observed at 81.5 and $69.0 \mathrm{ppm}$ confirmed 3,6-disubstituted B-D-galactose units. The signal observed at $32 \mathrm{ppm}$ may be attributed to acetone.

\section{Methylation analysis of PF1 and desulfated PF1}

The results of the methylation analysis of intact and desulfated PF1 are shown in Table 3. The methylated derivatives obtained from PF1 suggest the presence of a central core composed of 3- or 4-linked B-D-glucuronic acid with minor amounts of 3- or 4-linked 
galactose units. Almost 50\% of 3-linked glucuronic acid units are branched at $\mathrm{C}-2$. The branches of galactoses should be at $\mathrm{C}$ $6, \mathrm{C}-2$ or C-3 on disubstituted galactose. The fucose chains are made up of 3- and 4-linked fucose; in addition, minor amounts of 4linked fucose are branched at C-2 with chains of xylose and/or fucose. Desulfation eliminated about $76 \%$ of the sulfate groups in PF1. The 3,4-disubstituted fucosyl residues almost disappeared in the desulfated PF1, suggesting that most are sulfated at C-3, in agreement with NMR analysis and IR spectrum results. The high content of non-reducing fucose and xylopyranose terminal residues indicated that PF1 is a highly branched polymer.

\section{Anticoagulant activity}

The PT and the aPTT tests are used to distinguish the effects on extrinsic and intrin-

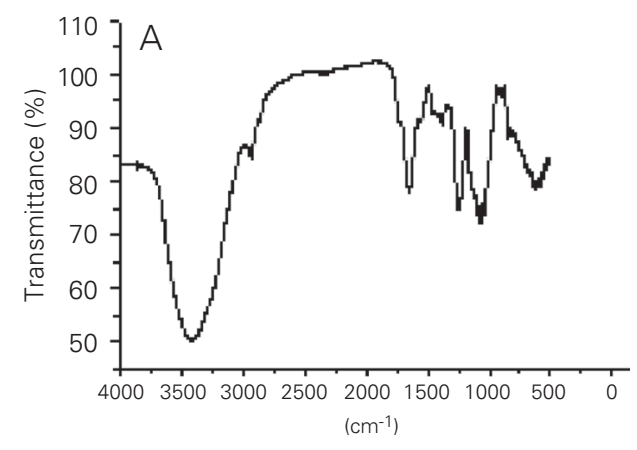

Figure 4. The Fourier transforminfrared (FT-IR) spectrum of fucans from Padina gymnospora at 4000 and $400 \mathrm{~cm}^{-1}$ in potassium bromide table. $A$, PF1 fucan; $B$, desulfated fucan.
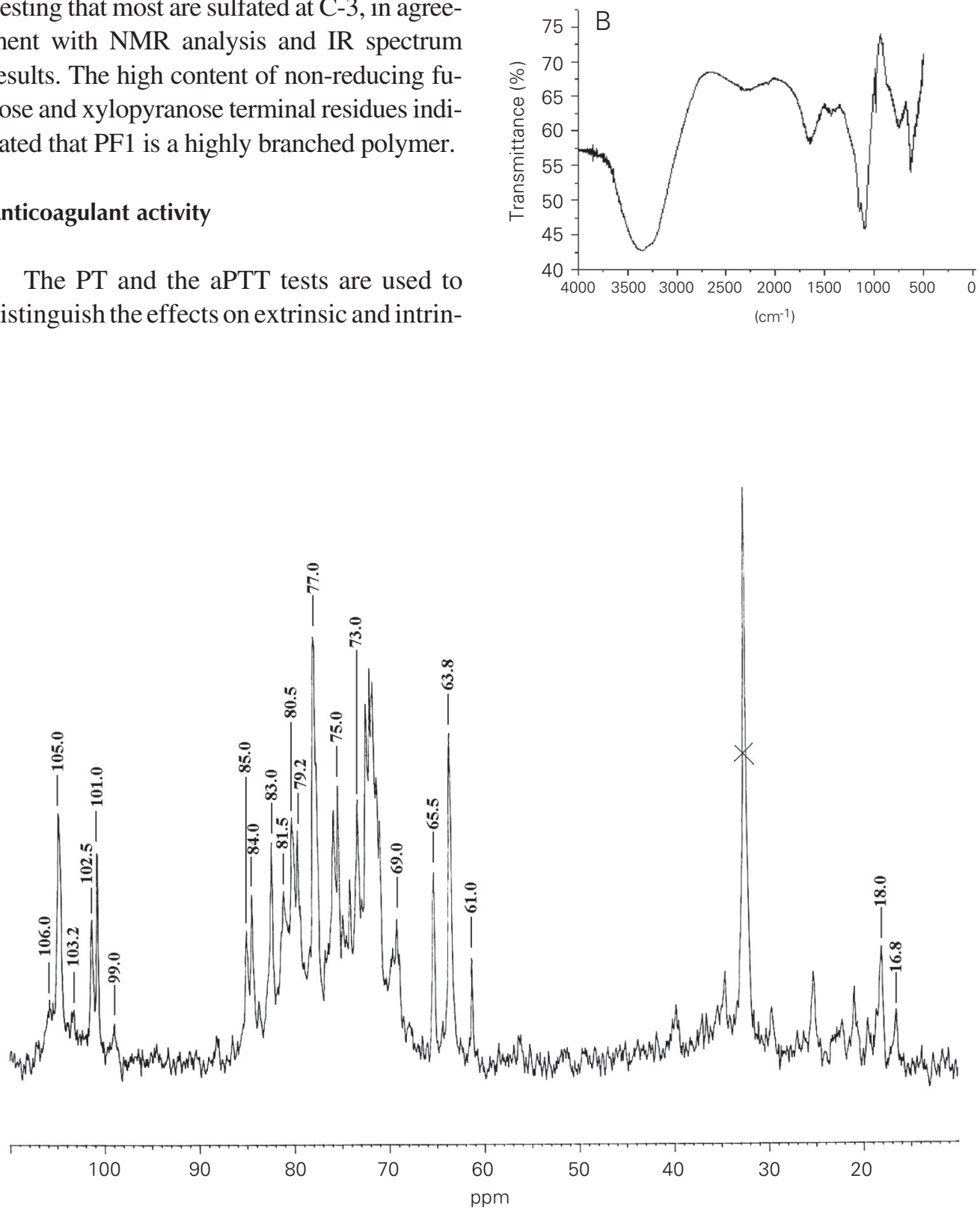

Figure $5 .{ }^{13} \mathrm{C}-\mathrm{NMR}$ spectrum at $500 \mathrm{MHz}$ of sulfated fucans from the brown alga Padina gymnospora. The spectrum was recorded at $60^{\circ} \mathrm{C}$ in a $\mathrm{D}_{2} \mathrm{O}$ solution of fraction PF1. 
sic coagulation pathways, respectively. None of the fractions had an anti-clotting effect when examined by the PT test. In contrast, the aPTT test revealed anticoagulant activity in fractions $0.8,1.0$, and 1.5. Fraction 1.0, with the highest anticoagulant activity, was

\begin{tabular}{lcccc} 
Table 3. Methylation analyses of native and desulfated PF1. \\
\hline Glycosyl residue & $\begin{array}{c}\text { Position of the } \\
\text { O-methyl group }\end{array}$ & $\begin{array}{c}\text { Deduced position } \\
\text { of substitution }\end{array}$ & $\begin{array}{c}\text { PF1 } \\
\text { (mol \%) }\end{array}$ & $\begin{array}{c}\text { Desulfated } \\
\text { PF1 (mol \%) }\end{array}$ \\
\hline Xylosyl & $2,3,4$ & Terminal & 9.0 & 5.7 \\
Fucosyl & 2,3 & 4 & 4.0 & 4.9 \\
& $2,3,4$ & Terminal & 5.2 & 6.0 \\
& 2,3 & 4 & 3.2 & 11.9 \\
Galactosyl & 2,4 & 3 & 9.4 & 10.3 \\
Glucuronic acid & 2 & 3,4 & 13.2 & 3.5 \\
& 3 & 2,4 & 5.3 & 4.5 \\
& 2,4 & 3,6 & 4.4 & 4.9 \\
& 2,4 & $2,4,6+2,3,6$ & 4.2 & 5.0 \\
& $2,4,6$ & 4 & 12.1 & 13.8 \\
& 4,6 & 3 & 16.5 & 16.9 \\
& & 2,3 & 13.5 & 12.6
\end{tabular}

Table 4. Anticoagulant activity of fucans from Padina gymnospora.

\begin{tabular}{|c|c|c|c|}
\hline \multirow[t]{3}{*}{ Polysaccharide } & \multicolumn{3}{|c|}{$\mathrm{aPTT}(\mathrm{s})$} \\
\hline & \multicolumn{3}{|c|}{ Amount of polysaccharide $(\mu \mathrm{g})$} \\
\hline & $20 \mu \mathrm{g}$ & $60 \mu \mathrm{g}$ & $100 \mu \mathrm{g}$ \\
\hline \multicolumn{4}{|l|}{ Fucan } \\
\hline 0.3 & nd & nd & nd \\
\hline 0.5 & nd & nd & nd \\
\hline 0.8 & $45 s$ & $74.9 \mathrm{~s}$ & $78.8 \mathrm{~s}$ \\
\hline 1.0 & $67.4 \mathrm{~s}$ & $109 \mathrm{~s}$ & $>240 \mathrm{~s}$ \\
\hline 1.5 & $46 s$ & $74.2 \mathrm{~s}$ & $105.6 \mathrm{~s}$ \\
\hline PF1 & $50.2 \mathrm{~s}$ & $119 \mathrm{~s}$ & $>240 \mathrm{~s}$ \\
\hline DPF1 & nd & nd & nd \\
\hline PF2 & nd & nd & nd \\
\hline \multirow[t]{3}{*}{ Heparin } & \multicolumn{3}{|c|}{ aPTT (s) } \\
\hline & \multicolumn{3}{|c|}{ Amount of polysaccharide $(\mu \mathrm{g})$} \\
\hline & $1 \mu \mathrm{g}$ & $6 \mu \mathrm{g}$ & $9 \mu \mathrm{g}$ \\
\hline UFH & $88 \mathrm{~s}$ & $>240 \mathrm{~s}$ & $>240 \mathrm{~s}$ \\
\hline LMW heparin (Clexane ${ }^{\circledR}$ ) & $47 \mathrm{~s}$ & $107 \mathrm{~s}$ & $>240 \mathrm{~s}$ \\
\hline
\end{tabular}

The standard deviation was $8-12 \%$ for three measurements for each sample. aPTT = activated partial thromboplastin time; UFH = unfractionated heparin; DPF1 = desulfated PF1; nd = anticoagulant activity not detectable; LMW = low molecular weight. The aPTT of normal human plasma was $38.9 \mathrm{~s}$. Heparin from bovine lung (175 IU) was used as reference. separated into PF1 and PF2 by Sephadex G75. Only PF1 showed anticoagulant activity (only 2.5-fold lesser than low molecular weight heparin). Desulfation of PF1 by solvolysis in dimethyl sulfoxide abolished its anticoagulant activity.

\section{Discussion}

In the present study, the brown seaweed Padina gymnospora was treated with acetone to remove lipids, pigments and mannitol. Proteolysis with maxataze resulted in a low level of contamination with proteins. This step was important because fucans bind to a large number of proteins by an ionexchange process. Subsequently, the extract was submitted to fractionation with different concentrations of acetone.

The electrophoretic profiles of the polysaccharides obtained in fractions $0.3,0.5$ and 0.8 showed the presence of two or three bands, while those from fractions 1.0 and 1.5 showed a single band each. All fractions were demonstrated to contain uronic acid, xylose, galactose, fucose, and sulfate. However, there were differences in the relative proportions of the sugars, suggesting the presence of different fucans in $P$. gymnospora. At least three different polysaccharides have been demonstrated in heterofucan preparations from Sargassum vulgare, Dictyota mertensis (15), Spatoglossum schröederi (24), and Sargassum stenophylum (29).

All fractions contained similar monosaccharide components. Fractions 0.3 and 0.5 had no anticoagulant activity, while fraction 0.8 had minimal activity, probably because this fraction is a mixture of polysaccharides, as observed in Figure 1. Due to the small amount of fraction 1.5 and the higher anticoagulant activity of fraction 1.0, we concentrated the structural studies on the latter fraction denoted PF1.

Chemical studies showed that PF1 is a glucuronofucan containing minor quantities of xylose and galactose and traces of man- 
nose. FT-IR studies revealed characteristic absorption bands of sulfated polysaccharides (5). There was notable absorption at 1264 $\mathrm{cm}^{-1}$ ( $\mathrm{S}=\mathrm{O}$ stretching) and $822 \mathrm{~cm}^{-1}$ (C-O-S bending of sulfates in an equatorial position) (24). The $822 \mathrm{~cm}^{-1}$ absorption is generally attributed to O-3 and/or O-2 sulfates in fucose residues (6). No absorption attributable to O-4 axial sulfates was found (around 840 $\left.\mathrm{cm}^{-1}\right)$. The molecular weight of PF1 (18 kDa) is similar to that reported for other brown seaweed fucans $(24,30,31)$ although in many cases products with values higher than 50,000 were also reported $(3,31)$.

Structural studies clearly show that several homofucans have large proportions of both $\alpha-(1 \rightarrow 3)$ and $\alpha-(1 \rightarrow 4)$ glycoside linkages with the sulfate groups at $\mathrm{C}-2$, without excluding the presence of other sulfate groups or branches at positions 2,3 or $4(4,5)$. However, heterofucans are more complex than homofucans. The glucuronic acid and fucose domains of the glucuronofucan PF1 were analyzed separately since one of them could be a linear backbone or side chain. Nagaoka et al. (31) proposed that a fucan from $C$. okamuranus contains a linear backbone of $(1 \rightarrow 3)$ linked fucose. Parts of its fucose units were substituted with $(1 \rightarrow 2)$ linked $\alpha$-glucuronic acid (29). Furthermore, Abdel-Fattah et al. (32) isolated a fucan from $S$. linifolium containing a central core made of B-D-glucuronic acid and B-D-mannose and Leite et al. (24) showed a xylofucoglucuronan composed of a core of $(1 \rightarrow 3)$ linked BD-glucuronic acid with branches at C-4 of $(1 \rightarrow 3)$ linked $\alpha$-fucose chains. Our data indicate that the fucose from PF1 was mostly substituted at C-2 with chains of $(1 \rightarrow 4)$ linked $\beta$-D-xylose.

Like many other native fucans, PF1 had a very complex ${ }^{13} \mathrm{C}$-NMR spectrum, which was difficult to interpret. Unambiguous assignment of all peaks was not possible due to peak overlapping. Several intense signals appeared in anomeric (101-101.5 ppm) and high-field (16.8-18.0 ppm) regions, a phe- nomenon typical of 3- and 4-linked $\alpha$ fucopyranosides (4). The presence of 3-Osulfated fucose was confirmed by the signals at $77.5 \mathrm{ppm}$ (C-3) and $80.5 \mathrm{ppm}$ (C-4), as also observed by Chevolot et al. (5). No signal was observed at 20-25 ppm, a fact that might indicate the presence of acetyl groups (3).

The methylation analysis of native and desulfated PF1 (Table 3) suggested a highly branched molecule with approximately $14 \%$ of non-reducing terminal units. The fucose appeared mainly methylated at C-2 and dimethylated at C-2 and C-4. A significant amount of 3-O-methyl and 2,3-di- $O$-methylfucose was also found, together with terminal 2,3,4-tri- $O$-methylfucose. After desulfation, the amount of 2,3-di- $O$-methylfucose increased mostly at the expense of 2-O-methylfucose. Minor increases of 2,3,4-tri- $O$ methylfucose were also observed, while the proportion of other fucose residues remained mostly unchanged. These results suggest that the "fucan" (fucose domain) chains were formed by large amounts of $(1 \rightarrow 4)$ linked fucose units ( $\pm 46 \%$ sulfated at C-3) together with lesser quantities of $(1 \rightarrow 3)$ linked fucose units. This structure profile is similar to that observed in homofucans. This is the first report of a fucan with fucose sulfated only at C-3. The $(1 \rightarrow 4)$ linked fucose units $( \pm 25 \%)$ could be branched through $\mathrm{C}-2$ by $(1 \rightarrow 4)$ linked xylose residues or fucosyl/xylosyl endchain residues, as previously observed by Leite et al. (24) in a fucan from Spatoglossum schröederi. The glucuronic domain was formed by $(1 \rightarrow 3)$ and $(1 \rightarrow 4)$ linked glucuronic acid units together with a smaller quantity of 3- and 4-linked galactose units. Almost $50 \%$ of 3-linked glucuronic acid units are branched at $\mathrm{C}-2$. The branches should be at C-6, C-2 or C-3 in disubstituted galactose.

Several studies have reported the anticoagulant activity of fucans from brown algae $(8,33,34)$. It was previously reported that only homofucans induce anticoagulant activity $(5,35,36)$. However, relatively few stud- 
ies have interpreted the biological activity of fucans in terms of molecular structure. The anticoagulant activity of fucan is unlikely to be merely a charge density effect; rather it depends critically on the distribution pattern of sulfate groups (33) and the size of the molecule (35). Chevolot et al. (5) demonstrated that the anticoagulant activity of a homofucan from $A$. nodosum with a high proportion of $(1 \rightarrow 4)$ linkage was related to $2-O$-sulfation and 2,3-disulfation (5). It was also observed that desulfation of PF1 resulted in loss of anticoagulant activity. Thus, the presence of 3 - $O$-sulfated $(1 \rightarrow 4)$ linked fucose in PF1 could be related to the higher anticoagulant activity of this heterofucan.

\section{Acknowledgments}

The authors are indebted to Daniel Leung, MSc from University of Iowa, for revising the paper. We are grateful to Centro Nordestino de Aplicação e Uso da Ressonância Magnética Nuclear(CENAUREMN), Universidade Federal do Ceará (UFC), for the NMR measurements. We would like to thank Dr. Paulo A.S. Mourão, Universidade Federal do Rio de Janeiro, for carrying out the methylation studies.

\section{References}

1. Kloareg B \& Quatrano RS (1988). Structure of cell wall of marine algae and ecophysiological function of matrix polysaccharides. Oceanography and Marine Biology, an Annual Review, 26: 259-315.

2. Percival EGV \& McDowell RH (1967). Chemistry and Enzymology of Marine Algal Polysaccharides. Academic Press, London, UK, 219.

3. Chizhov AO, Dell A, Morris HR, Haslam SM, McDowell RA, Shashkov AS, Nifant'ev NE, Khatuntseva EA \& Usov AI (1999). A study of fucoidan from the brown seaweed Chorda filum. Carbohydrate Research, 320: 108-119.

4. Bilan MI, Grachev AA, Ustuzhanina NE, Shasshkov AS, Nifantiev EN \& Usov A (2002). Structure of a fucoidan from the brown seaweed Fucus evanescens. C. Ag. Carbohydrate Research, 337: 719-730.

5. Chevolot L, Foucault A, Chaubet F, Kervarec N, Sinquin C, Fisher A \& Boisson-Vidal C (1999). Further data on the structure of brown seaweed fucans: relationships with anticoagulant activity. Carbohydrate Research, 319: 154-165.

6. Patankar MS, Oehninger L, Barnett $T$, Williams RL \& Clark GF (1993). A revised structure for fucoidan may explain some of its biological activities. Journal of Biological Chemistry, 268: 2177021776.

7. Mulloy B, Mourão PAS \& Gray E (2000). Structure/function studies of anticoagulant sulphated polysaccharides using NMR. Journal of Biotechnology, 77: 123-135.

8. Grauffel V, Kloareg B, Mabeau S, Durand P \& Josefonficz J (1989). New natural polysaccharides with potent antithrombotic activity: Fucans from brown algae. Biomaterials, 10: 363-369.

9. Mauray S, Sternberg C, Theveniaux J, Millet J, Sinquin C, Tapon Bretaudiere J \& Fischer AM (1995). Venous antithrombotic and anticoagulant activities of a fucoidan fraction. Thrombosis and Haemostasis, 74: 1280-1285.

10. Blondin C, Fischer AM, Boisson-Vidal C, Kazatchkine MD \& Jozefonvicz J (1994). Inhibition of complement activation by natural sulfated polysaccharides (fucans) from brown seaweed. Molecular Immunology, 31: 247-253.

11. Rocha HAO, Franco CRC, Trindade ES, Carvalho LCM, Veiga SS,
Leite EL, Dietrich CP \& Nader HB (2001). A fucan from the brown seaweed Spatoglossum schröederi inhibits Chinese hamster ovary cell adhesion to several extracellular matrix proteins. Brazilian Journal of Medical and Biological Research, 34: 621-626.

12. Schaeffer DJ \& Krylov VS (2000). Anti-HIV extracts and compounds from algae and cyanobacteria. Ecotoxicology and Environmental Safety, 45: 208-227.

13. Liu J, Haroun-Bouhedja F \& Boisson-Vidal C (2000). Analysis of the in vitro inhibition of mammary adenocarcinoma cell adhesion by sulphated polysaccharides. Anticancer Research, 20: 3265-3272.

14. Albuquerque IRL, Queiroz KCS, Alves LG, Santos EA, Leite EL \& Rocha HAO (2004). Heterofucans from Dictyota menstrualis have anticoagulant activity. Brazilian Journal of Medical and Biological Research, 37: 167-171.

15. Dietrich CP, Farias GGM, Abreu LRD, Leite EL, Silva LF \& Nader HB (1995). A new approach for characterization of polysaccharides from algae: Presence of four main acidic polysaccharides in three species of the class Phaeophyceae. Plant Science, 108: 143-153.

16. Dische Z (1962). Color reactions of hexuronic acids. In: Whistler RL \& Wolfrom ML (Editors), Methods of Carbohydrate Chemistry. Academic Press, London, UK, 484-488.

17. Dubois M, Gilles KA, Hamilton JK, Rebers PA \& Smith F (1956). Colorimetric method for determination of sugars, and related substances. Analytical Chemistry, 28: 350-356.

18. Dische Z (1962). Color reactions of 6-deoxy-, 3-deoxy- and 3,6dideoxyhexoses. In: Whistler RL \& Wolfrom ML (Editors), Methods of Carbohydrate Chemistry. Academic Press, London, UK, 501503.

19. Dodgson KS \& Price RG (1962). A note on the determination of the ester sulphate content of sulphated polysaccharides. Biochemical Journal, 84: 106-110.

20. Vilela-Silva ACES, Castro MO, Valente AP, Biermann HC \& Mourão PAS (2002). Sulfated fucans from the egg jellies of the closely related sea urchins Strongylocentrotus droebachiensis and Strongylocentrotus pallidus ensure species-specific fertilization. Journal of 
Biological Chemistry, 277: 379-387.

21. Kosakai M \& Yosizawa Z (1975). A rapid method for separation and identification of several hexuronic acids and hexuronic acid-containing oligosaccharides. Analytical Biochemistry, 78: 425-429.

22. Lowry OH, Farr AL, Rosebrough NJ \& Randall RJ (1951). Protein measurement with the Folin phenol method. Journal of Biological Chemistry, 193: 265-275.

23. Dietrich CP \& Dietrich SMC (1977). Electrophoretic behavior of acidic mucopolysaccharides by agarose gel electrophoresis. Journal of Chromatography, 130: 299-304.

24. Leite EL, Medeiros MGL, Rocha HAO, Farias GGM, Silva LF, Chavante SF, Dietrich CP \& Nader HB (1998). Structure of a new fucan from the alga Spatoglossum schröederi. Plant Science, 132: 215-228.

25. Nagasawa K, Inove Y \& Kamata T (1977). Solvolytic desulfation of glycosaminoglycuronan sulfates with dimethyl sulfoxide containing water or methanol. Carbohydrate Research, 58: 47-55.

26. Mourão PAS \& Perlin AS (1987). Structural features of sulfated glycans from the tunic of Styela plicata (Chordata-Tunicata). A unique occurrence of $\mathrm{L}$-galactose in sulfated polysaccharides. European Journal of Biochemistry, 166: 431-436.

27. Ciucanu J \& Kerek F (1984). A simple and rapid method for the permethylation of carbohydrates. Carbohydrate Research, 131: 209-217.

28. Kircher HW (1960). Gas-liquid chromatography of methylates sugars. Analytical Chemistry, 32: 1103-1106.

29. Duarte MER, Cardoso MA, Noseda MD \& Cerezo AS (2001). Structural studies on fucoidans from the brown seaweed Sargas- sum stenophylum. Carbohydrate Research, 333: 281-293.

30. Ponce NMA, Pujol CA, Damonte EB, Flores ML \& Stortz CA (2003). Fucoidans from the brown seaweed Adenocystis utricularis: extraction methods, antiviral activity and structural studies. Carbohydrate Research, 338: 153-165.

31. Nagaoka M, Shibata H, Kimura-Takagi I, Hashimoto S, Kimura K, Makino T, Aiyama R, Ueyama S \& Yokokura T (1999). Structural study of fucoidan from Cladosiphon okamuranus Tokida. Glycoconjugate Journal, 16: 19-26.

32. Abdel-Fattah AF, Hussein MD \& Salem HM (1974). Studies of the purification and some properties of sargassan, a sulphated heteropolysaccharide from Sargassum linifolium. Carbohydrate Research, 33: 9-17.

33. Nader HB, Pinhal MAS, Baú EC et al. (2001). Development of new heparin-like compounds and other antithrombotic drugs and their interaction with vascular endothelial cells. Brazilian Journal of Medical and Biological Research, 34: 699-709.

34. Haroun-Bouhedja F, Moustafa E, Sinquin C \& Boisson-Vidal C (2000). Relation between sulfate groups and biological activities of fucans. Thrombosis Research, 100: 453-459.

35. Nardella A, Chaubert F, Boisson-Vidal C, Blondin C, Durand P \& Jozefonvicz J (1996). Anticoagulant low molecular weight fucans produced by radical process and ion exchange chromatography of high molecular weight fucans extracted from brown seaweed Ascophyllum nodosum. Carbohydrate Research, 289: 201-208.

36. Mourão PAS (2004). Use of sulfated fucans as anticoagulant and antithrombotic agents: future perspectives. Current Pharmaceutical Design, 10: 967-981. 